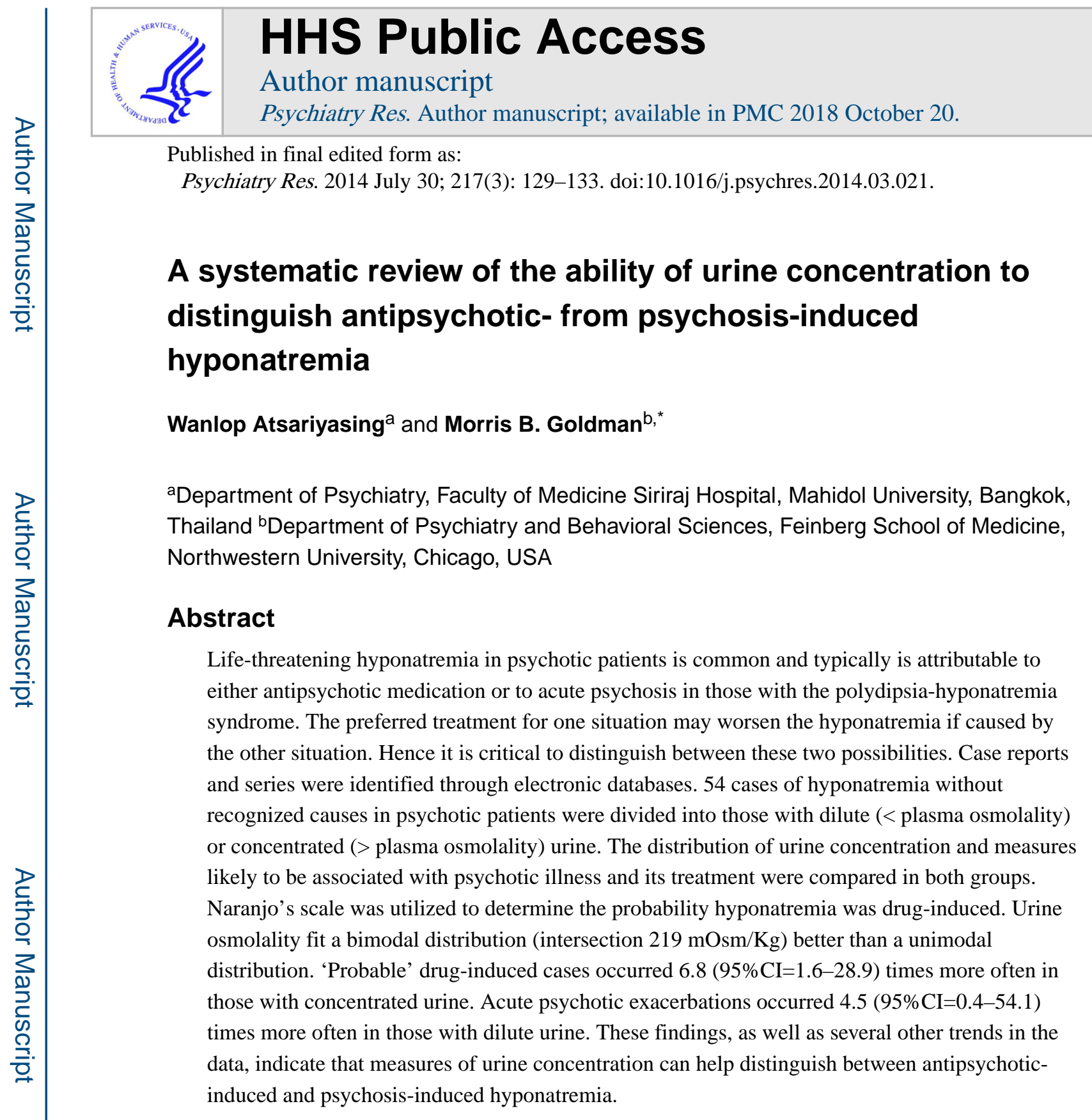

\title{
Keywords
}

Water intoxication; Schizophrenia; Vasopressin; Reset osmostat; SIADH

Corresponding author: Morris B. Goldman, MD; Department of Psychiatry; Northwestern University; 446 East Ontario, Suite 7-100; Chicago, IL 60611. Phone: 312695 2089. Fax: 708383 6387. m-goldman@northwestern.edu.

Publisher's Disclaimer: This is a PDF file of an unedited manuscript that has been accepted for publication. As a service to our customers we are providing this early version of the manuscript. The manuscript will undergo copyediting, typesetting, and review of the resulting proof before it is published in its final citable form. Please note that during the production process errors may be discovered which could affect the content, and all legal disclaimers that apply to the journal pertain.

Disclosures

Dr. Atsariyasing reports no conflict of interest.

Dr. Goldman and Dr. Atsariyasing contributed equally to this work. 


\section{1.) Introduction}

Life-threatening hyponatremia (water intoxication) is a relatively common condition in patients with psychotic illnesses (Renneboog et al., 2006; Hawken et al., 2009; Meulendijks et al., 2010; Williams and Kores, 2011). Often the electrolyte imbalance is attributable to prescribed medications, particularly diuretics or psychotropics such as anticonvulsant mood stabilizers, serotonin reuptake inhibitors, tricyclic antidepressants and antipsychotic medications (Liamis et al.,2008; Letmaier et al., 2012). In addition, nicotine as well as cigarette smoke per se can impair water balance (Robertson, 2006). This is especially apt to contribute to hyponatremia (Blum, 1984; Ismail, Z et al., 2010) because so many schizophrenic patients, particularly those at risk of hyponatremia (De Leon et al., 1996), smoke heavily. Hyponatremia typically resolves soon after the offending agent is stopped, but in the case of antipsychotics this may have a seemingly paradoxical effect if the hyponatremia is due to acute psychosis (Goldman et al., 1997; Meulendijks et al., 2010). This is because acute psychosis has also been associated with impaired water excretion (Targowla, 1923), primary polydipsia (Hoskins and Sleeper, 1933) and water intoxication (Barahal, 1938) well before antipsychotics were discovered. After their introduction, the literature is replete with reports indicating antipsychotic medication both contributes to (Meulendijks et al., 2010) and ameliorates (Dubovsky et al., 1973; Hariprasad et al., 1980; Canuso and Goldman, 1999; Liamis et al.,2008) hyponatremia. Currently perhaps $40 \%$ of psychotic patients admitted with unexplained hyponatremia are not taking antipsychotic medication (Williams and Kores, 2011).

Both antipsychotic medication and acute psychosis induce dilutional hyponatremia, which occurs when fluid intake overwhelms renal diluting capacity. The retained water swells all body tissues thus producing cerebral edema and ultimately cerebral compression by the skull (water intoxication). Under normal circumstances, hyponatremia can be prevented by varying urine dilution. Urine concentration is primarily regulated by the antidiuretic hormone, arginine vasopressin (AVP), which is secreted from the brain and then acts in the kidney. Decreases in plasma osmolality inhibit AVP secretion, in which case the normal kidney excretes huge amounts of water ( 20 liters/day).

Dilutional hyponatremia typically occurs due to either a relatively fixed impairment in the ability to produce dilute urine, or a variable impairment which lessens as the hyponatremia worsens. Depending on the plasma osmolality at which urine begins to be concentrated (osmotic set point), the patient may either present with symptomatic or asymptomatic hyponatremia (Robertson, 2006). Hyponatremia with other psychotropics has been associated with both fixed and variable impairments (Meulendijks et al., 2010), while acute psychosis has been consistently associated with the variable impairment (Hariprasad et al., 1980; Vieweg et al., 1986; Goldman et al., 1988; Kishimoto et al., 1989; Delva et al., 1990; Ohsawa et al., 1993). The mechanism appears to be attributable to psychosis lowering the osmotic set point for AVP secretion (Goldman et al., 1997) perhaps due to a stress diathesis that is associated with the underlying psychiatric illness (Goldman et al., 2007; Goldman, 2009; Goldman et al., 2011). The contribution of the elevated AVP to the hyponatremia is demonstrated by its rapid reversal with AVP antagonists (Josiassen et al., 2008; Josiassen et al., 2012). All classes of antipsychotic drugs are associated with hyponatremia (Mannesse et 
al., 2010), and currently there are no published guidelines to aid clinicians whether to increase or decrease antipsychotic medication. In the absence of controlled studies, we conducted a systematic review of published cases of medicated psychotic patients with unexplained hyponatremia who had concurrent measures of urine dilution.

\section{2.) Methods}

\subsection{Data sources and study selection}

136 articles were identified from the MEDLINE database from 1960 to September 2012 using the following MeSH terms: hyponatremia, inappropriate ADH syndrome, antipsychotic agents and English language (see Flow Diagram Figure 1). Ninety-one more were drawn from a recent comprehensive review of antipsychotic-induced hyponatremia authored by Meulendijks (et al., 2010). Forty-one duplicates were identified, leaving 186 to be screened. None were controlled studies, and all were either single or a series of case reports. Eighty-one of these articles were excluded on the basis of the abstract because they did not describe psychotic patients. The remaining 105 articles as well as 11 more drawn from these articles' references were evaluated. Seventeen of these 116 articles were excluded because they were not relevant, 31 because they did not contain concurrent indices of urine dilution (neither urine osmolality nor urine specific gravity), 21 because the psychiatric diagnosis was not a primary psychotic disorder (schizophrenia, schizophreniform, schizoaffective, or psychosis NOS), and three for other reasons, yielding 64 psychotic hyponatremic patients (44 articles) on antipsychotic therapy and with concurrent measures of urine dilution on presentation (Supplemental Table 2).

\subsection{Data extraction}

Serum sodium, plasma osmolality, urine osmolality, urine specific gravity and urine sodium were recorded as were concurrent medications that could potentially account for hyponatremia (Liamis et al., 2008). Variables drawn from guidelines for adverse event reporting (Kelly et al., 2007), and hypothesized measures distinguishing drug-induced from psychosis-induced cases were identified in each report.

Ten cases ( antidepressants) were taking other medications recognized to cause hyponatremia leaving a final sample of 54 inpatients (39 articles). Assessment of whether a case was an adverse drug reaction was based on Naranjo's probability scale (Naranjo et al., 1981). This assessment was the primary outcome measure since it could be scored in all cases. Scores on this scale range from -4 to +13 and are categorized as 'unlikely' ( -4 to 0$)$, 'possible' (1 to 4 ), 'probable' (5 to 8) and 'certain' (9 to 13). Secondary outcomes were: antipsychotic dose (transformed to defined-daily dose (DDD)) (ATC/DDD Index WHO, 2012); presence of acute psychotic exacerbation on admission; presence of polydipsia (per author); time from initiation of current antipsychotic to onset of hyponatremia; and the effect of antipsychotic discontinuation ('dechallenge') and of antipsychotic rechallenge with the same medication on hyponatremia. These measures were not available for all cases. Assessments were made by one of the authors (WA) who sought input from the remaining author on the rare occasion that the correct response was not evident.

Psychiatry Res. Author manuscript; available in PMC 2018 October 20. 


\subsection{Data analysis}

Subjects were grouped according to whether their urine was dilute or concentrated at presentation, i.e. whether urine osmolality was lower or higher than concurrent plasma osmolality. While the division is somewhat arbitrary, it is physiologically significant and bias-free (Robertson, 2006). Eight of the 54 cases had only urine specific gravity, and if specific gravity was $<1.010$ we placed the case in the dilute group since this is a common cutoff for dilute urine (Voinescu et al., 2002). In any event, urine specific gravity was $\leq$ 1.004 for seven of these cases and was 1.015 for the eighth case. Three cases had only plasma sodium available, so plasma osmolality was estimated as $2 \times$ plasma sodium +10 (Ross and Christie, 1969). The associated urine osmolality in all four instances was either 30 $\mathrm{mOsm} / \mathrm{Kg}$ more or less than this calculated plasma osmolality, so grouping was likely to be accurate.

\subsection{Statistical analysis}

We used a Gaussian mixture model to fit 1- and 2-gaussians to the urine osmolality values, and utilized Bayesian and Akaike information criterion (AIC) to determine whether unimodal or the bimodal fit was more consistent with the data and Akaike weights to define conditional probabilities (Wagenmakers and Farrell, 2004). Continuous outcome and other measures were compared with two tailed independent sample t-tests, while Pearson's Chi Square was conducted for categorical data, applying Fisher's exact test if expected cell counts were less than five. To address the possible role of rater bias in scoring whether a case was an adverse drug reaction, we also compared groups on Naranjo measures for cases only rated by Meulendijks (et al, 2010).

\section{3.) Results}

Data for 64 hyponatremic psychotic inpatients receiving antipsychotic therapy, each with concurrently measured urine concentration, were extracted from 44 articles (Figure 1). Ten had recognized causes for their hyponatremia and were excluded from further analysis (See Supplementary Table 1). 34 of the remaining 54 cases had dilute urine and 20 had concentrated urine $(\mathrm{P}=0.06)$ (Table 1). The two groups resembled each other on most demographic, clinical and plasma measures. In particular, mean age and plasma osmolality were similar (concentrated group: 246, dilute group: $239 \mathrm{mOsm} / \mathrm{Kg}$ ) and the vast majority of patients in both groups were noted to be polydipsic. Urine sodium concentration was higher in subjects with concentrated urine consistent with their more persistent AVP activity, values in those with dilute urine were still elevated suggestive of residual AVP activity.

A bimodal model fit the distribution of urine osmolalities (Akaike Information Criteria: 604.7, Bayesian Information Criteria: 613.9) better than a unimodal model ((AIC: 615.3, BIC: 619.0; weight 0.0049) with an intersection at $219 \mathrm{mOsm} / \mathrm{Kg}$ (Figure 2), suggesting two different processes were responsible for the hyponatremia. Concentrated urine was more frequently associated with adverse drug reactions than dilute urine (Table 1). Indeed, the odds of having 'probable' versus 'possible' drug-induced hyponatremia was 6.8 (95\% CI $(1.6-28.9)$ times higher in those with concentrated urine. This difference remained significant when only the cases rated by Meulendijks (et al., 2010) were assessed (Chi- 
square $4.22, d f=1, \mathrm{P}=0.05)$. On the other hand, a psychotic exacerbation on admission associated with dilute urine (OR 4.5, 95\% CI= 0.4 - 54.1). Those with concentrated urine, on average, were taking twice as high a dose of neuroleptic but were on it for only $1 / 8^{\text {th }}$ as long as those with dilute urine. Because of marked intersubject variation these differences did not approach significance (i.e. $\mathrm{P}$ z.30) (Table 1). All five of the patients with concentrated urine redeveloped hyponatremia when rechallenged, while the single patient with dilute urine did not. Because of the small numbers involved, this only showed a trend toward significance $(\mathrm{P}$ $=.17$ ). None of these latter differences, however, reached statistical significance. While very few patients in either group redeveloped severe hyponatremia when their antipsychotic medication was stopped, these patients were typically fluid restricted during their hospitalization.

\section{4.) Discussion}

Life-threatening hyponatremia was first identified in psychotic patients in the 1930's (Barahal, 1938) and over the subsequent years has been associated with both antipsychotic medication and exacerbations of the underlying psychiatric disorder (Meulendijks et al., 2010). No published guidelines for distinguishing these two possibilities have been reported. In the absence of controlled trials, we completed a systematic review of case reports and case series in the English literature. We eliminated cases with recognized causes of hyponatremia leaving 54 cases of unexplained hyponatremia in medicated patients with a primary psychotic disorder, each having concurrent measures of urine concentration (Figure 1).

We found that the distribution of urine osmolalities across these cases fit a bimodal distribution which intersected at $219 \mathrm{mOsm} / \mathrm{Kg}$, suggestive of their being two distinct processes (Figure 2). As we anticipated (Targowla, 1923; Vieweg et al., 1986; Goldman et al., 1988; Kishimoto et al., 1989; Delva et al., 1990; Ohsawa et al., 1993; Goldman et al., 1997), probable drug-induced hyponatremia occurred six times as often in cases with concentrated urine and psychotic exacerbations occurred four times as often in cases with dilute urine (Table 1). While duration of drug treatment was about one-eighth as long, medication dosage was twice as high, and recurrence of hyponatremia upon rechallenge occurred exclusively in those with concentrated urine, the differences between those with concentrated and dilute urine did not reach significance. Still, taken a whole these data all point to a greater role for antipsychotic medication in those with concentrated urine. In contrast polydipsia was about as frequently observed in both categories consistent with others' findings that this is an unreliable measure of increased intake (de Leon et al., 1996).

There are several limitations to this study. The results are based on a review of case reports, raising issues about the generalizability, as well as reliability and comparability of the data. For instance, sampling of urine likely varied in relationship to concurrent measures of plasma concentration. The conclusion that urine concentration is bi-modal assumes the pooled findings from these case reports constitute a sample of the population of interest. The assessment of whether a psychotic exacerbation or polydipsia was present on admission assumes that authors were equally reliable and diligent in making this assessment. These

Psychiatry Res. Author manuscript; available in PMC 2018 October 20. 
assumptions are undoubtedly violated, but what may be reasonable is to assert there is unlikely to be a systematic bias favoring one possibility or the other.

While the majority of cases of 'probable' antipsychotic-induced hyponatremia occurred with concentrated urine, two cases did occur with dilute urine (Table 1). We suspect that hyponatremia may in fact arise from antipsychotic treatment in some patients with dilute urine. Possible mechanisms are anticholinergic-induced polydipsia secondary to dry mouth (Mannesse et al., 2010) in a patient with reset osmostat, or medication-induced reset osmostat due to hypotension in a patient with primary polydipsia (Robertson, 2006; Meulendijks et al., 2010). Indeed, in one of the two cases the patient was receiving thioridazine which has potent anticholinergic effects which could induce polydipsia. In the other the patient was receiving loxapine, which is an alpha-adrenergic antagonic that induces hypotension and potentially reset osmostat. Hence, urine concentration is unlikely to be a completely reliable marker, and other clinical history and findings should be considered as well.

We recommend that clinicians presented with an acutely hyponatremic psychotic patient take a careful history, determine concurrent urine and plasma osmolality, impose targeted fluid restriction and rigorously search for reversible causes (Vieweg and Leadbetter, 1997; Siegal, 2008). While methodologic issues summarized above limit the applicability of the findings, they do provide some guidance for managing patients with hyponatremia which cannot be attributed to other recognized causes. Hence, we recommend if urine is concentrated the current antipsychotic be switched to another structural class (without anticholinergic properties). If urine is dilute and the antipsychotic dose is subtherapeutic, we recommend the dose be increased. If the dose is therapeutic another agent should be prescribed. If hyponatremia does not rapidly resolve, the clinician should review the differential diagnosis and consider clozapine treatment (Canuso and Goldman, 1999). Patients should be observed closely until they tolerate ad lib access to water without developing symptomatic hyponatremia.

\section{Supplementary Material}

Refer to Web version on PubMed Central for supplementary material.

\section{Acknowledgments}

Dr. Goldman and Dr. Atsariyasing had full access to all of the data in the study and take responsibility for the integrity of the data and the accuracy of the data analysis. Dr. Goldman was a recipient of grant funds from Otsuka for studies with tolvaptan (Samsca).

\section{REFERENCES}

ATC/DDD Index. WHO Collaborating Center for Drug Statistics Methodology. 2012 [Accessed October 16, 2012] www.whocc.no/atc_ddd_index/.

Barahal HS. Water intoxication in a mental case. Psychiatry Quaterly. 1938; 12:767-771.

Blum A. The possible role of tobacco cigarette smoking in hyponatremia of long-term psychiatric patients. Journal of the American Medical Association. 1984; 252:2864-2865. [PubMed: 6492367] 
Canuso CM, Goldman MB. Clozapine restores water balance in schizophrenic patients with polydipsia-hyponatremia syndrome. Journal of Neuropsychiatry and Clinical Neurosciences. 1999; 11:86-90. [PubMed: 9990561]

de Leon J, Dadvand M, Canuso C, Odom-White A, Stanilla J, Simpson GM. Polydipsia and water intoxication in a long-term psychiatric hospital. Biological Psychiatry. 1996; 1:28-34.

Delva NJ, Crammer JL, Lawson JS, Lightman SL, Sribney M, Weier BJ. Vasopressin in chronic psychiatric patients with primary polydipsia. British Journal of Psychiatry. 1990; 157:703-712. [PubMed: 2279208]

Dubovsky SL, Grabon S, Berl T, Schrier RW. Syndrome of inappropriate secretion of antidiuretic hormone with exacerbated psychosis. Annals of Internal Medicine. 1973; 79:551-554. [PubMed: 4748273]

Goldman MB, Luchins DJ, Robertson GL. Mechanisms of altered water metabolism in psychotic patients with polydipsia and hyponatremia. New England Journal of Medicine. 1988; 318:397-403. [PubMed: 3340117]

Goldman MB, Robertson GL, Luchins DJ, Hedeker D, Pandey GN. Psychotic exacerbations and enhanced vasopressin secretion in schizophrenic patients with hyponatremia and polydipsia. Archives of General Psychiatry. 1997; 54:443-449. [PubMed: 9152098]

Goldman MB, Gnerlich J, Hussain N. Neuroendocrine responses to a cold pressor stimulus in polydipsic hyponatremic and in matched schizophrenic patients. Neuropsychopharmacology. 2007; 32:1611-1621. [PubMed: 17164813]

Goldman MB. The mechanism of life-threatening water imbalance in schizophrenia and its relationship to the underlying psychiatric illness. Brain Research Reviews. 2009; 61:210-220. [PubMed: 19595703]

Goldman MB, Wang L, Wachi C, Daudi S, Csernansky J, Marlow-O'Connor M, Keedy S, Torres I. Structural pathology underlying neuroendocrine dysfunction in schizophrenia. Behavioural Brain Research. 2011; 218:106-113. [PubMed: 21093493]

Hariprasad MK, Eisinger RP, Nadler IM, Padmanabhan CS, Nidus BD. Hyponatremia in psychogenic polydipsia. Archives of Internal Medicine. 1980; 140:1639-1642. [PubMed: 7458496]

Hawken ER, Crookall JM, Reddick D, Millson RC, Milev R, Delva N. Mortality over a 20-year period in patients with primary polydipsia associated with schizophrenia: a retrospective study. Schizophrenia Research. 2009; 107:128-133. [PubMed: 18984069]

Hoskins RG, Sleeper FH. Organic functions in schizophrenia. A.M.A. Archives of Neurology and Psychiatry. 1933; 30:123-140.

Ismail Z, Syms J, Blumberger D, George TP. Varenicline induced polydipsia and hyponatremia in a patient with schizophrenia. Schizophrenia Research. 2010; 119:268. [PubMed: 20178890]

Josiassen RC, Goldman M, Jessani M, Shaughnessy RA, Albazzaz A, Lee J, Ouyang J, Orlandi C, Czerwiec F. Double-blind, placebo-controlled, multicenter trial of a vasopressin V2-receptor antagonist in patients with schizophrenia and hyponatremia. Biological Psychiatry. 2008; 64:10971100. [PubMed: 18692175]

Josiassen RC, Curtis JL, Shaughnessy RA, Filmyer DM, Geboy AG, Skuban N, Czerwiec F. Vaptans: a potential new approach for treating chronic hyponatremia in psychotic patients. Clinical Schizophrenia and Related Psychoses. 2012; 6:21-26. [PubMed: 22453866]

Kelly WN, Arellano FM, Barnes J, Bergman U, Edwards RI, Fernandez AM, Freedman SB, Goldsmith DI, Huang KA, Jones JK, McLeay R, Moore N, Stather RH, Trenque T, Troutman WG, van Puijenbroek E, Williams F, Wise RP. Guidelines for submitting adverse event reports for publication. Drug Safety. 2007; 30:367-373. [PubMed: 17472416]

Kishimoto T, Hirai M, Ohsawa H, Terada M, Matsuoka I, Ikawa G. Manners of arginine vasopressin secretion in schizophrenic patients--with reference to the mechanism of water intoxication. Japanese Journal of Psychiatry and Neurology. 1989; 43:161-169. [PubMed: 2796026]

Letmaier M, Painold A, Holl AK, Vergin H, Engel R, Konstantinidis A, Kasper S, Grohmann R. Hyponatraemia during psychopharmacological treatment: results of a drug surveillance programme. International Journal of Neuropsychopharmacology. 2012; 15:739-748. [PubMed: 21777511] 
Liamis G, Milionis H, Elisaf M. A review of drug-induced hyponatremia. American Journal of Kidney Diseases. 2008; 52:144-153. [PubMed: 18468754]

Mannesse CK, van Puijenbroek EP, Jansen PAF, van Marum RJ, Souverein PC, Egberts TCG. Hyponatraemia as an adverse drug reaction of antipsychotic drugs: a case-control study in VigiBase. Drug Safety. 2010; 33:569-578. [PubMed: 20553058]

Meulendijks D, Mannesse CK, Jansen PAF, van Marum RJ, Egberts TCG. Antipsychotic-induced hyponatraemia: a systematic review of the published evidence. Drug Safety. 2010; 33:101-114. [PubMed: 20082537]

Moher D, Liberati A, Tetzlaff J, Altman DG. The PRISMA Group (2009). Preferred Reporting Items for Systematic Reviews and Meta-Analyses: The PRISMA Statement. Annals of Internal Medicine. 2009; 151:264-269. [PubMed: 19622511]

Naranjo CA, Busto U, Sellers EM, Sandor P, Ruiz I, Roberts EA, Janecek E, Domecq C, Greenblatt DJ. A method for estimating the probability of adverse drug reactions. Clinical Pharmacology and Therapeutics. 1981; 30:239-245. [PubMed: 7249508]

Ohsawa H, Kishimoto T, Shimayoshi N, Matsumura K, Tahara K, Kitera K, Higashiura N, Noriyama Y, Matsumoto H, Hirai M. Atrial natriuretic peptide and arginine vasopressin secretion in schizophrenic patients. Acta Psychiatrica Scandinavica. 1993; 88:130-134. [PubMed: 8213206]

Renneboog B, Musch W, Vandemergel X, Manto MU, Decaux G. Mild chronic hyponatremia is associated with falls, unsteadiness, and attention deficits. American Journal of Medicine. 2006; 119:71.

Robertson GL. Regulation of arginine vasopressin in the syndrome of inappropriate antidiuresis. American Journal of Medicine. 2006; 119(7 suppl. 1):S36-S42. [PubMed: 16843083]

Ross EJ, Christie SB. Hypernatremia. Medicine. 1969; 48:441-473. [PubMed: 4951234]

Siegel AJ. Hyponatremia in psychiatric patients: update on evaluation and management. Harvard Review of Psychiatry. 2008; 16(1):13-24. [PubMed: 18306096]

Targowla R. Des troubles fonctionnel du rein dans les maladies mentales. L'excretion del'eau (Kidney malfunction and mental illness: water excretion). Bulletins et mémoires de la Société médicale des hôpitaux de Paris. 1923; 47:1711-1715.

Vieweg WV, David JJ, Rowe WT, Peach MJ, Veldhuis JD, Spradlin WW. Correlation of cigaretteinduced increase in serum nicotine levels with arginine vasopressin concentrations in the syndrome of self-induced water intoxication and psychosis (SIWIP). Canadian Journal of Psychiatry. 1986; 31:108-111. [PubMed: 3697900]

Vieweg WV, Leadbetter RA. Polydipsia-hyponatraemia syndrome: epidemiology, clinical features and treatment. CNS Drugs. 1997; 7:121-138. [PubMed: 23338131]

Voinescu GC, Shoemaker M, Moore H, Khanna R, Nolph KD. The relationship between urine osmolality and specific gravity. American Journal of the Medical Sciences. 2002; 323:39-42. [PubMed: 11814141]

Wagenmakers EJ, Farrell S. AIC model selection using Akaike weights. Psychonomic Bulletin and Review. 2004; 11:192-196. [PubMed: 15117008]

Williams ST, Kores RC. Psychogenic polydipsia: comparison of a community sample with an institutionalized population. Psychiatry Research. 2011; 187:310-311. [PubMed: 21122924] 


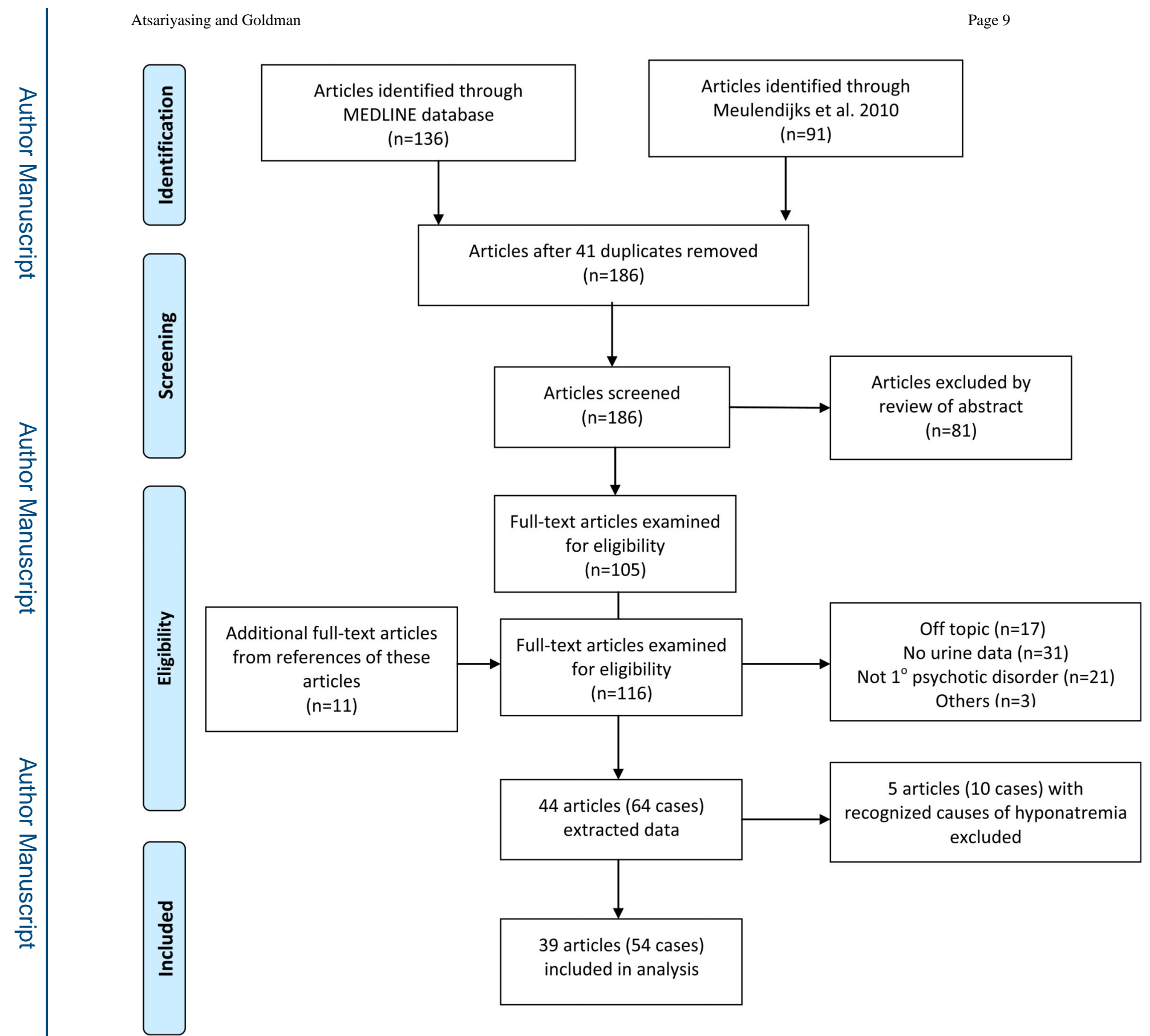

Figure 1.

Flow Diagram (adapted from the PRISMA 2009 Flow Diagram (Moher et al., 2009)) 


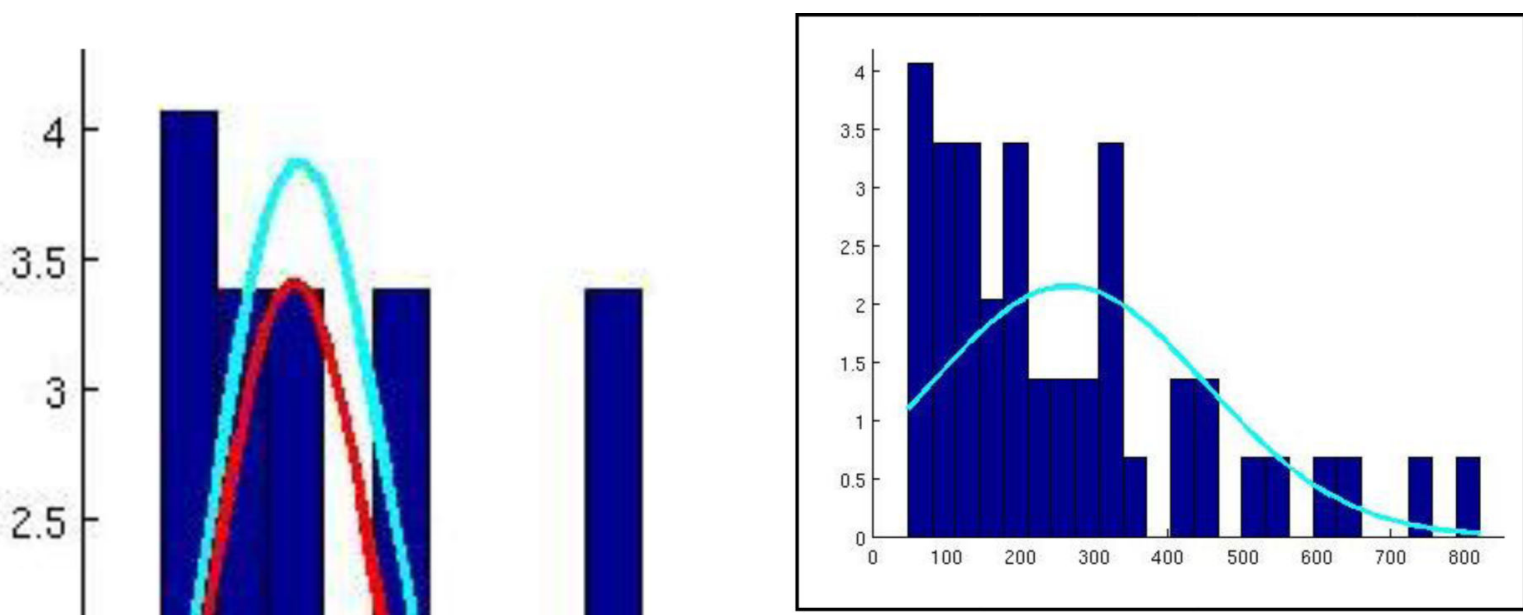

1.5

Urine Osmolality $(\mathrm{mOsm} / \mathrm{Kg})$

Figure 2.

The figure shows the results of a Gaussian mixture model fit of 2-gaussians to the urine osmolality data in medicated psychotic patients with unexplained hyponatremia. The unimodal model is shown in the inset. The likelihood the bimodal fit the data better was < . 005 . 
Table 1

Hyponatremic patients with concentrated $(>\mathrm{pOsm})$ vs dilute $(<\mathrm{pOsm})$ urine $^{a}$

\begin{tabular}{|c|c|c|c|}
\hline Characteristics & Concentrated & Dilute & $P$ value \\
\hline No. of cases & 20 & 34 & 0.06 \\
\hline Age, mean $(\mathrm{SD})$, years & $46.1(12.1)$ & $41.5(11.4)$ & 0.18 \\
\hline \multicolumn{4}{|l|}{ Gender } \\
\hline Male, No. & 11 & 21 & 0.62 \\
\hline Female, No. & 9 & 13 & \\
\hline Plasma sodium, mean (SD), mmol/liter & $116.2(6.3)$ & $115.4(6.7)$ & 0.67 \\
\hline Plasma osmolality, mean (SD), mOsm/Kg & $246.1(14.9)(\mathrm{n}=18)$ & $239.0(16.2)(\mathrm{n}=27)$ & 0.13 \\
\hline Urine osmolality, mean (SD), mOsm $/ \mathrm{Kg}$ & $443(160)(n=19)$ & $138.8(59.5)(\mathrm{n}=27)$ & $<0.001$ \\
\hline Urine specific gravity, mean (SD) & $1.012(0.005)(\mathrm{n}=6)$ & $1.004(0.003)(\mathrm{n}=14)$ & $<0.001$ \\
\hline Urine sodium, mean $(\mathrm{SD}), \mathrm{mEq} / \mathrm{L}$ & $73.4(55.1)(\mathrm{n}=13)$ & $31.0(23.5)(\mathrm{n}=16)$ & 0.02 \\
\hline \multicolumn{4}{|l|}{ Water loading test $b$} \\
\hline Impaired, No. & 2 & 0 & $0.14^{c}$ \\
\hline Normal, No. & 1 & 2 & \\
\hline \multicolumn{4}{|l|}{ Polydipsic $^{d}$} \\
\hline Yes, No. & 8 & 20 & 0.61 \\
\hline No, No. & 2 & 3 & \\
\hline Duration of mental disorder, mean (SD), years & $13.6(9.8)(\mathrm{n}=12)$ & $13.3(5.7)(\mathrm{n}=10)$ & 0.93 \\
\hline \multicolumn{4}{|l|}{ Psychotic exacerbation } \\
\hline Yes, No. & 6 & 9 & 0.20 \\
\hline No, No. & 3 & 1 & \\
\hline DDD-equivalent dosage, mean (SD) & $3.6(8.0)(\mathrm{n}=16)$ & $1.8(1.5)(\mathrm{n}=14)$ & 0.40 \\
\hline Current drug duration, mean (SD), days & $46.4(45.6)(\mathrm{n}=10)$ & $388.2(1023)(\mathrm{n}=10)$ & 0.30 \\
\hline \multicolumn{4}{|l|}{ Antipsychotic } \\
\hline First generation, No. & 17 & 29 & \\
\hline Second generation, No. & 3 & 3 & 0.447 \\
\hline Combined or unclassified, No. & 0 & 2 & \\
\hline \multicolumn{4}{|l|}{ Dechallenge $^{e}$} \\
\hline Negative, No. & 11 & 12 & 0.50 \\
\hline Positive, No. & 2 & 1 & \\
\hline \multicolumn{4}{|l|}{ Rechallenge } \\
\hline Positive, No. & 5 & 0 & 0.17 \\
\hline Negative, No. & 0 & 1 & \\
\hline \multicolumn{4}{|l|}{ Adverse Drug Reaction } \\
\hline Probable, No. & 8 & 2 & $0.003^{c}$ \\
\hline Possible, No. & 12 & 32 & \\
\hline
\end{tabular}

Psychiatry Res. Author manuscript; available in PMC 2018 October 20. 
${ }^{c}$ Adjusted for expected cell size by Fishers exact test

${ }^{d}$ Per author's assessment only

Whether stopping medication led to worsening of hyponatremia 